\title{
Long-term survival and major outcomes in post-cardiotomy extracorporeal membrane oxygenation for adult patients in cardiogenic shock
}

\author{
Paolo Meani ${ }^{1,2}$, Matteo Matteucci ${ }^{1,3}$, Federica Jiritano ${ }^{1}$, Dario Fina ${ }^{1}$, Francesco Panzeri ${ }^{4}$, Giuseppe M. Raffa ${ }^{1,5,6}$, \\ Mariusz Kowalewski ${ }^{1}$, Nuccia Morici ${ }^{7,8}$, Giovanna Viola ${ }^{7}$, Alice Sacco ${ }^{7}$, Fabrizio Oliva ${ }^{7}$, Amal Alyousif ${ }^{1}$, \\ Sam Heuts ${ }^{1}$, Martijn Gilbers ${ }^{1}$, Rick Schreurs ${ }^{1}$, Jos Maessen ${ }^{1}$, Roberto Lorusso ${ }^{1}$ \\ ${ }^{1}$ Department of Cardio-Thoracic Surgery, Maastricht University Medical Centre (MUMC+), Maastricht, The Netherlands; ${ }^{2}$ Department of Intensive \\ Care Unit, Maastricht University Medical Centre (MUMC+), Maastricht, The Netherlands; ${ }^{3}$ Department of Cardiac Surgery, Circolo Hospital, \\ University of Insubria, Varese, Italy; ${ }^{4}$ Milano Bicocca University, Milan, Italy; ${ }^{5}$ Department for the Treatment and Study of Cardiothoracic Diseases \\ and Cardiothoracic Transplantation, ${ }^{6}$ Department of Anesthesia and Intensive Care, IRCCS-ISMETT (Instituto Mediterraneo per i Trapianti e \\ Terapie ad alta specializzazione), Palermo, Italy; ${ }^{7}$ De Gasperis Cardio Center, ASST Grande Ospedale Metropolitano Niguarda Ca' Granda, Milan, \\ Italy; ${ }^{8}$ Department of Clinical Sciences and Community Health, Università degli Studi, Milan, Italy \\ Correspondence to: Paolo Meani, MD. Cardio-Thoracic Surgery Department, Maastricht University Medical Centre, P. Debyelaan 25 - 6202 AZ, \\ Maastricht, The Netherlands. Email: paolo.meani@mumc.nl.
}

\begin{abstract}
Extracorporeal membrane oxygenation (ECMO) in the veno-arterial (VA) configuration is an established method for the treatment of refractory cardiogenic shock. Such a condition characterizes the postoperative course of approximatively $1 \%$ of cardiac surgery patients. Although some studies have reported ECMOrelated short-term results, little is known about the long-term outcomes of VA-ECMO therapy in the postcardiotomy setting. Therefore, an extensive literature search was conducted regarding articles published after 1990 reporting postoperative ECMO use. PubMed, EMBASE and Web of Science were searched for sources. In-hospital mortality was high in post-cardiotomy VA-ECMO patients, ranging from $24.8 \%$ to $52 \%$. Long-term results were poorly reported. However, based on the limited information available, hospital survivors showed a favorable outcome, with improvement in overall clinical condition, quality of life and limited hospital readmission for cardiac-related events. To conclude, in-hospital outcome in post-cardiotomy ECMO is often unfavorable, post-discharge results show satisfactory condition, with stable improvement of overall patient clinical status and low rate of hospital readmission and cardiac-related adverse events. Data reporting is, however, scarce and hence new and detailed studies are still warranted to investigate such aspects.
\end{abstract}

Keywords: Extracorporeal membrane oxygenation (ECMO); cardiogenic shock; heart failure; cardiac surgery

Submitted Nov 07, 2018. Accepted for publication Dec 01, 2018.

doi: $10.21037 /$ acs.2018.12.04

View this article at: http://dx.doi.org/10.21037/acs.2018.12.04

\section{Introduction}

Since the first implantation by Hill and colleagues (1), extracorporeal membrane oxygenation (ECMO) has become an established treatment option for adult patients with refractory cardiogenic shock (2), providing temporary cardiac and respiratory support. Approximately $1 \%$ of adult patients who undergo cardiac surgery develop postcardiotomy cardiogenic shock (PCS) and require mechanical circulatory support (MCS) beyond the conventional medical or mechanical treatments to support the failing heart (1-5). Because of its quick availability, easy and rapid applicability and reliability, ECMO support has become a more and more attractive option, particularly in post- 
cardiotomy (PC) setting (1-3). Another option available is short-term ventricular assist devices (VADs), either uni- or biventricular, but complexity, lack of lung support, and costs has limited its wide application (6-8).

PC-ECMO has become the most frequent indication for ECMO in the United States (3), however, its exponential increase has not been paralleled by improved results, but rather to the contrary (5). Although during the last 20 years advances in technique and management were achieved, ECMO results have not been satisfactory. Prevalence, trends of use, indications and implant information, types of patient, specific procedures for whom it is being used, in-hospital patient management and short- and long-term outcomes have peculiar features in the PC-ECMO setting. Information on post-hospital discharge outcomes after veno-arterial (VA)-ECMO (ranging from 1 year to 10 years) have shown overall survival rates ranging from $17 \%$ to $40 \%$ (9-11), but little attention has been given to other factors related to the long-term prognosis (12-14). Furthermore, despite numerous publications that have shown ECMOrelated short and medium-term results, specific reports about PC-ECMO have been limited and usually related to single-center experience. In addition, some reports have shown some critical illness in survivors, with some long-term functional impairment in physical, cognitive and psycho-social settings $(15,16)$. A targeted analysis of these aspects would have a relevant implication in the daily practice of ECMO users. This review, therefore, had the aim to present the current information about PC-ECMO in adult patients, providing an evaluation of the long-term mortality and morbidity for VA-ECMO.

\section{Methods}

A literature search was run on PubMed, EMBASE and Web of Science covering the time period between January 1990 and August 2018. Publications that appeared before 1990 were not included due to the remarkable dissimilarity in intensive care unit management, surgical techniques and ECMO-related technology. Two operators independently performed the computerized literature search using the following keywords: "Postoperative extracorporeal membrane oxygenation", "Postoperative extracorporeal life support", "Post-Cardiotomy", "Mechanical Circulatory Support", "Temporary Mechanical Circulatory Support", "Perioperative Cardio-Pulmonary Assistance", "Perioperative Cardio-Pulmonary Failure", "Percutaneous Mechanical Circulatory Support", "Postoperative
Cardiogenic Shock", "Postoperative Cardiac Arrest", "Postcardiotomy Cardiac Arrest", "Post-Cardiotomy Cardiac Failure", "Post-Cardiotomy Complications", "ARDS and cardiac surgery", "Post-Cardiotomy Respiratory Dysfunction". Information regarding target populations, ECMO implantation site and major outcomes were collected and systematically recorded. Only publications in English were considered.

Only studies specifically conducting on ECMO in perior post-operative adults (>18 years of age) undergoing cardiac surgery (see Table 1) were collected, leading to a careful assessment of short-term outcomes and evaluation of post-discharge follow-up. Exclusion criteria included published PC-ECMO series, case reports, or case series, reporting less than 10 patients, as these would not allow for a meaningful cohort analysis of PC-ECMO patients.

\section{Results}

Overall, 242 published papers were selected, reviewed and carefully analyzed. The flow-chart showing the literature search and selection for final information analysis is shown in Figure 1. Table 1 shows the main results. Fifteen studies were selected, included 2,852 patients supported with VAECMO due to PCS. The mean age was 63.7 years. VAECMO was placed using central and peripheral cannulation. In-hospital survival ranged from $24.8 \%$ to $52 \%$, whereas 1 -year survival ranged from $16.5 \%$ to $47.6 \%$. Regarding long-term survival, the best rate reported was $37 \%$ (Table 1). However, each study has considered different timing, therefore any consistent and comprehensive evaluation was not feasible. A total of six articles, enrolling 2,033 patients, reported 5-year survival, while only two studies (1,188 subjects) provided data for 10-year survival. Corresponding reported survival ranged from $13.7 \%$ to $32 \%$ and from $9.7 \%$ to $17.6 \%$, respectively. The created variable regarding the survival difference, representing the difference between one-year and in-hospital survival, ranged from $0 \%$ to $21 \%$, thereby confirming that longterm mortality was relatively low in these patients, although these findings were hampered by the maximum follow-up at 10 years from the original operation.

Table 2 shows the described major outcomes found in this literature selection. These mainly consisted of five fields reported: New York Heart Association Class, rehospitalizations, medical expenditures, quality of life and specific outcomes regarding dead and survived patients. From the limited data and information available, it is 


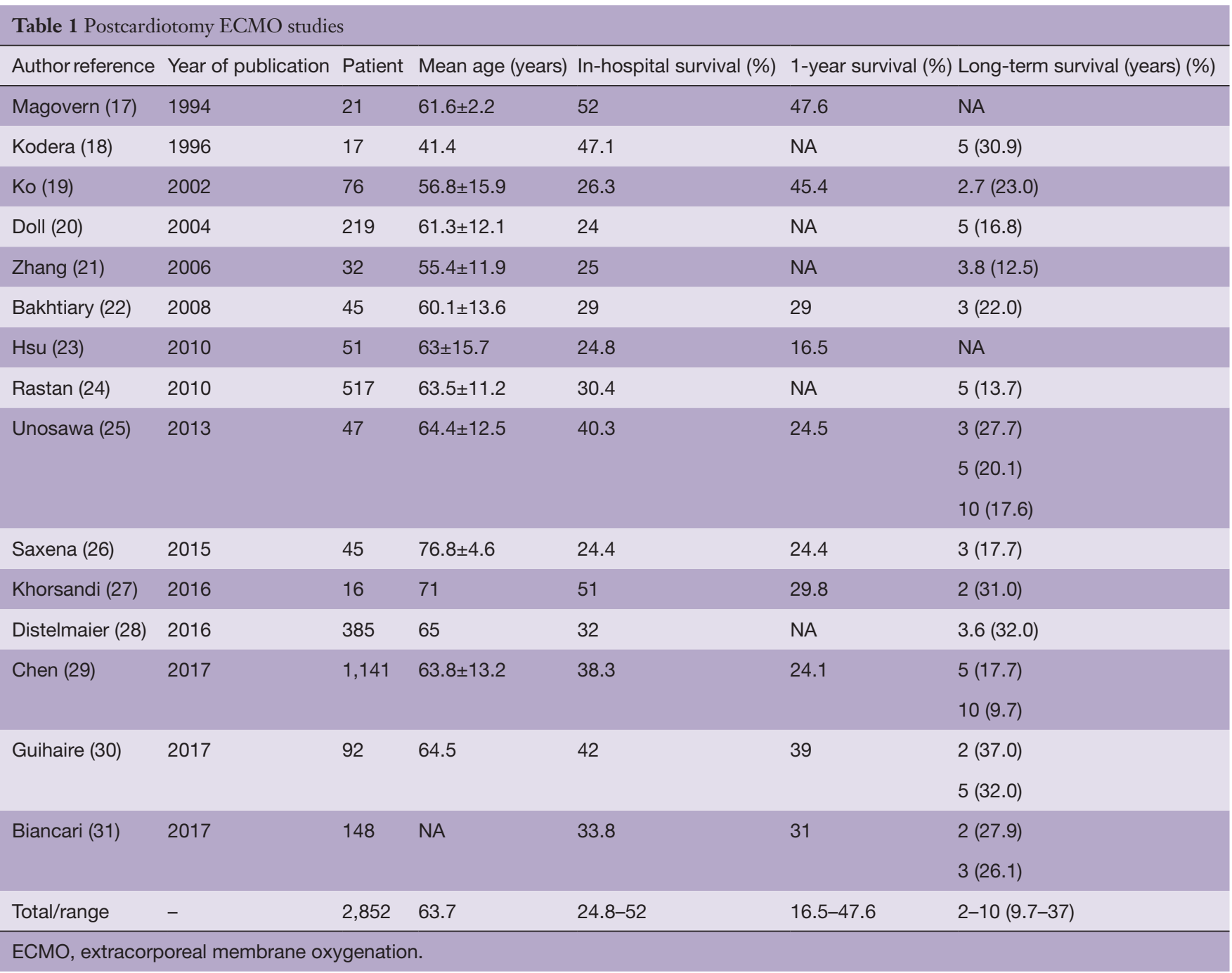

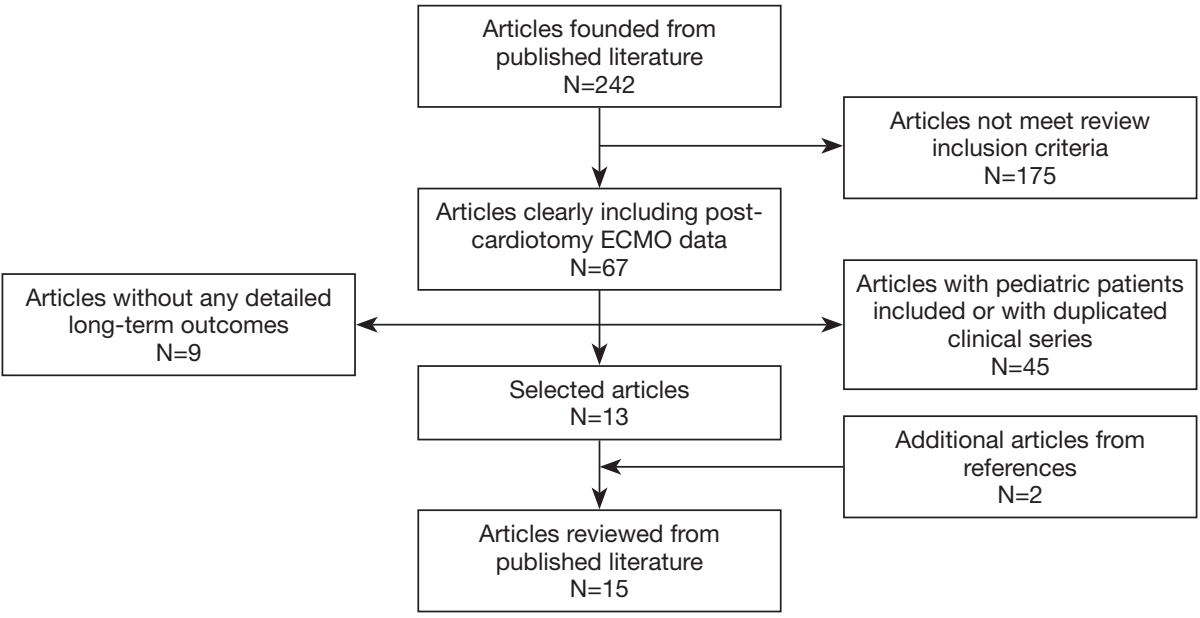

Figure 1 Literature search and selection flow chart. 


\begin{tabular}{|c|c|}
\hline Outcomes & Details/results \\
\hline \multicolumn{2}{|l|}{ NYHA class } \\
\hline Ko (19) & NYHA class II or I \\
\hline Doll (20) & NYHA class II \\
\hline Bakhtiary (22) & NYHA class II or III \\
\hline Unosawa (25) & NYHA class I or II \\
\hline Saxena (26) & NYHA class I, II, III and IV \\
\hline Khorsandi (27) & NYHA class I-II \\
\hline \multicolumn{2}{|l|}{ Readmission } \\
\hline \multirow[t]{2}{*}{ Doll (20) } & Rate: $37.8 \%$ \\
\hline & $\begin{array}{l}\text { Causes: routine cardiac investigations, } \\
\text { pneumonia, non-cardiac-related surgical } \\
\text { interventions }\end{array}$ \\
\hline \multirow[t]{2}{*}{ Bakhtiary (22) } & Rate: $60 \%$ \\
\hline & $\begin{array}{l}\text { Causes: pneumonia, end-stage renal failure } \\
\text { requiring dialysis }\end{array}$ \\
\hline \multirow[t]{2}{*}{ Chen (29) } & $\begin{array}{l}\text { Mean } \mathrm{N} \text { of readmissions: } 0.68 ; 95 \% \mathrm{Cl} \text {, } \\
0.60-0.78\end{array}$ \\
\hline & Higher in PC patients support with ECMO \\
\hline \multicolumn{2}{|l|}{ Expenditures } \\
\hline Chen (29) & Greater in PC patients support with ECMO \\
\hline \multicolumn{2}{|l|}{ Quality of life } \\
\hline Guihaire (30) & $\begin{array}{l}\text { Self-care without any limitations in all } \\
\text { cases, minor problems considering other } \\
\text { dimensions }\end{array}$ \\
\hline \multicolumn{2}{|c|}{ Specific outcomes } \\
\hline Ko (19) & Sudden death, pneumonia \\
\hline Hsu (23) & Cardiac arrest, severe infection \\
\hline Unosawa (25) & $\begin{array}{l}\text { Cardiac events, heat stroke, ruptured iliac } \\
\text { artery aneurysm, subarachnoid hemorrhage, } \\
\text { pneumonia unknown cause }\end{array}$ \\
\hline Saxena (26) & End-stage heart disease \\
\hline Guihaire (30) & Major cardiac event, non-cardiac events \\
\hline Bakhtiary (22) & $\begin{array}{l}\text { Congestive heart failure, pneumonia, end- } \\
\text { stage renal failure }\end{array}$ \\
\hline
\end{tabular}

NYHA, New York Heart Association; PC, post-cardiotomy; $\mathrm{N}$, number; $\mathrm{Cl}$, confidence interval; $\mathrm{ECMO}$, extracorporeal membrane oxygenation. evident that overall PC-ECMO patients have a favorable prognosis, with the vast majority maintaining a satisfactory clinical condition, limited readmission rate and favorable quality of life.

\section{Discussion}

The incidence of refractory PCS in adult cardiac surgical patients ranges from $0.5 \%$ to $1.5 \%(24,31,32)$. PCS is a rare but dreadful complication. The first PCS treatment step is pharmacologic. However, the overwhelming majority of PCS is unresponsive to high dosages of inotropes. Therefore, intra-aortic balloon pump support is frequently adopted, even if this strategy presents well-known limitations, particularly during active resuscitation (33). As a direct consequence, VA-ECMO has been increasingly considered and applied in PCS. Such a temporary MCS is a salvage therapy, often representing the only prompt and life-saving technique in refractory PCS cases. Although VA-ECMO support is a well-established and effective procedure in the presence of PCS, the in-hospital mortality rate is still high, with an unsatisfactory in-hospital outcome. In fact, the reported in-hospital survival has ranged from $24.8 \%$ to $52 \%$ in several case series, a 1 -year survival ranging from $16.5 \%$ to $47.6 \%$ and gradually ranging from almost $10 \%$ to $37 \%$ when the late survival is considered (20-30). These data clearly show how the majority of PCECMO patients die during the hospitalization, showing a fall in the mortality rate after being discharged. This would mean that achieving the discharge might be one of the most important predictors of good long-term outcome. Therefore, it is clear that high in-hospital mortality remains the Achilles' heel of ECMO. The importance of survival to discharge—and not just successful weaning-was illustrated by Ko et al., who studied 76 patients undergoing ECMO support for refractory PCS. Although $60.5 \%$ of this cohort was successfully weaned from ECMO, only $26.3 \%$ survived to discharge. However, all survivors showed New York Heart Association (NYHA) I and II functional class at $32 \pm 22$ months of follow-up (19).

However, the current literature doesn't allow to make any substantial consideration regarding long-term outcomes. Lack of data and absence of standardized data collection made our analysis extremely undetailed and difficult to interpret. Under this light, the overall literature clearly shows a lot of cloudy aspects. von Bahr et al. reported a high risk of death, $15 \%$ within 90 days of hospital discharge increasing to $24 \%$ at long-term follow-up of 3 years (34). 
In contrast, de Waha et al. showed $15.7 \%$ survival with satisfactory functional outcomes at 18 months in patients with refractory cardiogenic shock undergoing ECLS (35). Therefore, another crucial point that should be detailed better is the quality of life of survivors.

\section{Other outcomes}

The NYHA class is a remarkable scale for defining patient functional status (36). Six out of sixteen papers reported this parameter as part of long-term results in PC-ECMO patients. Doll et al. showed all survivors in NYHA class II at late follow-up (20). On the contrary, the experience presented by Saxena et al. (26). interestingly described a heterogenous functional status, which included patients in class III and IV. However, the overwhelming majority of these studies reported survivors in NYHA class I or II (20-30). This might lead to speculation that the PCECMO survivors, once overcoming the ECMOrelated hospital course, may show a favorable long-term functional status. Guihaire et al. supported the latter finding by measuring the long-term quality of life (30). In this study, the health-related quality of life was assessed among PC-ECMO survivors 2 years after ECMO support using the EQ-5D survey (37) and the EQ visual analogue scale. No self-care limitations were found in any cases. Minor problems, however, were found considering other dimensions came out (e.g., mobility, usual activities, pain and anxiety) (37). Therefore, PC-ECMO survivors seem to achieve a long-term good functional status and quality of life. On the other hand, three papers included readmission rate in their analysis. The latter fluctuated from $37.8 \%$ to $60 \%$. Under this light, Chen et al. (29) observed a greater mean number of readmissions for any cause during the follow-up in patients who required ECMO compared with those who didn't need the ECMO support after surgery. As a consequence, patients supported with ECMO for PCS might have an increased need of future hospitalizations. Chen et al. also found greater medical expenditure in PC-ECMO group during only the first year, which disappeared in the following checks. This finding might be related with the increase number of readmissions in this population, underlying the high disease burden amongst these patients. Finally, scant data are available regarding the specific causes of death or the new onset of morbidities in survivors. Nevertheless, infections and cardiac events might be considered the most common causes of death or morbidity (20-30).

\section{Conclusions}

In conclusion, the long-term survival in PC-ECMO seems to be strongly influenced by the early hospitalized critical phase, after which the survival slightly drops but remains satisfactory. Little is known, however, regarding other long-term outcome parameters after ECMO treatment in PC setting. The current lack of dedicated registries, limited data collection within studies and postdischarge follow-up in PC-ECMO patients, and a few centers with this specific experience and high number of cases, are likely the most important causes for such poor information. Further investigations are urgently needed in order to better show post-discharge outcomes in adult patients submitted to PC-ECMO.

\section{Acknowledgements}

None.

\section{Footnote}

Conflicts of Interest: Prof. Lorusso declares that he is Principal Investigator of the PERSIST-AVR Study (sponsored by LivaNova) and is Consultant for Medtronic. The other authors have no conflicts of interest to declare.

\section{References}

1. Hill JD, O’Brien TG, Murray JJ, et al. Prolonged extracorporal oxygenation of acute posttraumatic respiratory failure (shock-lung syndrome). N Engl J Med 1972;286:629-34.

2. McCarthy FH, McDermott KM, Kini V, et al. Trends in U.S. extracorporeal membrane oxygenation use and outcome: 2002-2012. Semin Thorac Cardiovasc Surg 2015;27:81-8.

3. Sauer CM, Yuh DD, Bonde P. Extracorporeal membrane oxygenation use increased $433 \%$ in adults in the United States from 2006 to 2011. ASAIO J 2015:61:31-6.

4. Maxwell BG, Powers AJ, Sheikh AY, et al. Resource use trends in extracorporeal membrane oxygenation in adults: an analysis of the Nationwide Inpatient Sample 19982009. J Thorac Cardiovasc Surg 2014;148;416-21.e1.

5. Whitman GJR. Extracorporeal membrane oxygenation for the treatment of postcardiotomy shock. J Thorac Cardiovasc Surg 2017;153:95-101.

6. Goldstein DJ, Oz MC. Mechanical support for 
postcardiotomy cardiogenic shock. Semin Thorac Cardiovasc Surg 2000;12:220-8.

7. Curtis JJ, McKenney-Knox CA, Wagner-Mann CC. Postcardiotomy centrifugal assis: a single surgeon's experience. Artif Organs 2002;26:994-7.

8. Jurmann MJ, Siniawski H, Erb M, et al. Initial experience with miniature axial flow ventricular assist devices for postcardiotomy heart failure. Ann Thorac Surg 2004;77:1642-7.

9. Combes A, Leprince P, Luyt CE, et al. Outcomes and long-term quality-of-life of patients supported by extracorporeal membrane oxygenation for refractory cardiogenic shock. Crit Care Med 2008;36:1404-11.

10. Lee SH, Chung CH, Lee JW, et al. Factors predicting early- and long-term survival in patients undergoing extracorporeal membrane oxygenation (ECMO). J Card Surg 2012;27:255-63.

11. Winters BD, Eberlein M, Leung J, et al. Long-term mortality and quality of life in sepsis: a systematic review. Crit Care Med 2010;38:1276-83.

12. Bottiroli M, Maraffi T, Decaria D, et al. In-hospital and long-term mortality after venoarterial ECMO for refractory cardiogenic shock. Crit Care 2015;19:P281.

13. Hodgson CL, Hayes K, Everard T, et al. Long-term quality of life in patients with acute respiratory distress syndrome requiring extracorporeal membrane oxygenation for refractory hypoxaemia. Crit Care 2012;16:R202.

14. Lindén VB, Lidegran MK, Frisen G, et al. ECMO in ARDS: a long-term follow-up study regarding pulmonary morphology and function and health-related quality of life. Acta Anaesthesiol Scand 2009;53:489-95.

15. Hashem MD, Nallagangula A, Nalamalapu S, et al. Patient outcomes after critical illness: a systematic review of qualitative studies following hospital discharge. Crit Care 2016;20:345.

16. Herridge MS, Tansey CM, Matte A, et al. Functional disability 5 years after acute respiratory distress syndrome. N Engl J Med 2011;364:1293-304.

17. Magovern GJ Jr, Magovern JA, Benckart DH, et al. Extracorporeal membrane oxygenation: preliminary results in patients with postcardiotomy cardiogenic shock. Ann Thorac Surg 1994;57:1462-8; discussion 1469-71.

18. Kodera K, Kitamura M, Hachida M, et al. Biventricular bypass with oxygenation for postcardiotomy ventricular failure. Artif Organs 1996;20:724-7.

19. Ko WJ, Lin CY, Chen RJ, et al. Extracorporeal membrane oxygenation support for adult postcardiotomy cardiogenic shock. Ann Thorac Surg 2002;73:538-45.
20. Doll N, Kiaii B, Borger M, et al. Five-year results of 219 consecutive patients treated with extracorporeal membrane oxygenation for refractory postoperative cardiogenic shock. Ann Thorac Surg 2004;77:151-7.

21. Zhang R, Kofidis T, Kamiya H, et al. Creatine kinase isoenzyme $\mathrm{MB}$ relative index as predictor of mortality on extracorporeal membrane oxygenation support for postcardiotomy cardiogenic shock in adult patients. Eur J Cardiothorac Surg 2006;30:617-20.

22. Bakhtiary F, Keller H, Dogan S, et al. Venoarterial extracorporeal membrane oxygenation for treatment of cardiogenic shock: clinical experiences in 45 adult patients. J Thorac Cardiovasc Surg 2008;135:382-8.

23. Hsu PS, Chen JL, Hong GJ, et al. Extracorporeal membrane oxygenation for refractory cardiogenic shock after cardiac surgery: predictors of early mortality and outcome from 51 patients. Eur J Cardiothorac Surg 2010;37:328-33.

24. Rastan AJ, Dege A, Mohr M, et al. Early and late outcome of 517 consecutive patients treated with extracorporeal membrane oxygenation for refractory postcardiotomy cardiogenic shock. J Thorac Cardiovasc Surg 2010;139:302-11.

25. Unosawa S, Sezai A, Hata M, et al. Long-term outcomes of patients undergoing ECMO for refractory postcardiotomy cardiogenic shock. Surg Today 2013;43:264-70.

26. Saxena P, Neal J, Joyce LD, et al. Extracorporeal membrane oxygenation support in postcardiotomy elderly patients: the Mayo Clinic experience. Ann Thorac Surg 2015;99:2053-60.

27. Khorsandi M, Shaikhrezai K, Prasad S, et al. Advanced mechanical circulatory support for post-cardiotomy cardiogenic shock: a 20-year outcome analysis in a nontransplant unit. J Cardiothorac Surg 2016;11:29-35.

28. Distelmaier K, Schrutka L, Binder C, et al. Cardiac arrest does not affect survival in post-operative cardiovascular surgery patients undergoing extracorporeal membrane oxygenation. Resuscitation 2016;104:24-7.

29. Chen SW, Tsai FC, Lin YS, et al. Long-term outcomes of extracorporeal membrane oxygenation support for postcardiotomy shock. J Thorac Cardiovasc Surg 2017;154:469-77.e2.

30. Guihaire J, Dang Van S, Rouze S, et al. Clinical outcomes in patients after extracorporeal membrane oxygenation support for post-cardiotomy cardiogenic shock: a singlecentre experience. Interact Cardiovasc Thorac Surg 2017;25:363-9.

31. Biancari F, Dalén M, Perrotti A. Venoarterial 
extracorporeal membrane oxygenation after coronary artery bypass grafting: Results of a multicenter study. Int J Cardiol 2017;241:109-14.

32. Fux T, Holm M, Corbascio M, et al. Venoarterial extracorporeal membrane oxygenation for postcardiotomy shock: risk factors for mortality. J Thorac Cardiovasc Surg 2018;156:1894-902.e3.

33. Bozbuga N. Postcardiotomy extracorporeal membrane oxygenation for refractory cardiogenic shock. J Thorac Cardiovasc Surg 2018;156:1903-4.

34. von Bahr V, Hultman J, Eksborg S, et al. Long-term survival in adults treated with extracorporeal membrane oxygenation for respiratory failure and sepsis. Crit Care

Cite this article as: Meani P, Matteucci M, Jiritano F, Fina D, Panzeri F, Raffa GM, Kowalewski M, Morici N, Viola G, Sacco A, Oliva F, Alyousif A, Heuts S, Gilbers M, Schreurs R, Maessen J, Lorusso R. Long-term survival and major outcomes in post-cardiotomy extracorporeal membrane oxygenation for adult patients in cardiogenic shock. Ann Cardiothorac Surg 2019;8(1):116-122. doi: 10.21037/acs.2018.12.04
Med 2017;45:164-70.

35. de Waha S, Fuernau G, Desch S, et al. Long-term prognosis after extracorporeal life support in refractory cardiogenic shock: results from a real-world cohort. EuroIntervention 2016;11:1363-71.

36. Holland R, Rechel B, Stepien K, et al. Patients' selfassessed functional status in heart failure by New York Heart Association class: a prognostic predictor of hospitalizations, quality of life and death. J Card Fail 2010;16:150-6.

37. Rabin R, de Charro F. EQ-5D: a measure of health status from the EuroQol Group. Ann Med 2001;33:337-43. 